\title{
EGOCENTRISMO IMPLÍCITO NO CONSUMO: UMA PESQUISA EXPERIMENTAL NO BRASIL
}

\section{IMPLICIT EGOTISM IN CONSUMPTION: AN EXPERIMENTAL RESEARCH IN BRAZIL}

\author{
Márcio de Oliveira Mota \\ Professor do Programa de Pós-Graduação em Administração - Universidade Estadual do Ceará \\ Fortaleza, CE, Brasil \\ E-mail: marcio@marciomota.com \\ Juliana Lopes de Moraes \\ Mestranda do Programa de Pós-Graduação em Administração - Universidade Estadual do Ceará \\ Fortaleza, CE, Brasil \\ E-mail: juh.lopes88@gmail.com
}

Felipe Augusto Marinho Amorim

Mestrando do Programa de Pós-Graduação em Administração - Universidade Estadual do Ceará

Fortaleza, CE, Brasil

E-mail: amorim.fam@gmail.com

\section{RESUMO}

O presente artigo tem como objetivo verificar como o egocentrismo implícito resultante de autoassociações positivas dos consumidores afeta sua intenção de compra e sua preferência pelos produtos. A partir de um plano experimental, foi verificado o gosto pelo produto e a intenção de compra nas seguintes situações: quando o produto apresenta letras que se relacionam com o nome do indivíduo (Estudo 1); quando os preços apresentados visualmente (como caracteres numéricos) fazem referência ao ano de nascimento do consumidor (Estudo 2); quando há visivelmente estampado referência a uma data religiosa a qual o consumidor faz parte (Estudo 3). Os resultados mostram que há propensão ao gosto pelo produto e intenção de compra nos Estudos 1 e 3, mas estes efeitos não foram significantes no Estudo 2, demonstrando que a autoassociação com o ano de nascimento não é um aspecto que altera o gosto pelo produto e nem a inclinação para a compra em consumidores brasileiros.

Palavras-chave: Egocentrismo Implícito. Psicologia do Consumidor. Pesquisa Experimental. Marketing. Autoassociação positiva.

\section{ABSTRACT}

This article aims to examine how the implicit egotism resulting of self-positive associations of consumers affects their purchase intent and its preference for products. From an experimental plan, has occurred the liking of product and purchase intent in the following situations: when the product has letters that relate to the individual's name (Study 1); when prices presented visually (as numeric characters) refer to the consumer's birth year (Study 2); when has clearly stamped a reference of religious date to which the consumer is part (Study 3). The results show that there is propensity to liking the product and purchase intent in Studies 1 and 3, but these effects were not significant in Study 2, demonstrating that selfassociation with the year of birth is not an aspect that alters the liking for the product and nor the inclination to purchase at Brazilian consumers.

Keywords: Implicit Egotism. Consumer behavior. Experimental Research. Marketing. Self-positive associations.

Data de submissão: 4 de setembro de 2015.

Data de aprovação: 5 de abril de 2018. 


\section{INTRODUÇÃO}

Sabe-se que os processos inconscientes podem influenciar o comportamento humano nas diversas esferas da sua existência. Os profissionais e estudiosos do marketing, conhecedores de que isso também afeta os hábitos de consumo e o momento da comparação e escolha de determinados produtos ou serviços, manipulam esses processos que se sucedem nas mentes dos consumidores com o propósito de intensificar as vendas ou fomentar a escolha por marcas e produtos específicos.

Esse manuseio de informações de forma que afetem o inconsciente humano já foi objeto de muitos debates e contestações quando algumas empresas optaram por fazer uso de mensagens subliminares como formas de divulgação dos seus produtos. Outros modelos apelativos de sensibilização e influência de compra empregando-se os processos inconscientes também estão sendo desenvolvidos e estudados, como, o processo de associação de características pessoais com produtos afim de impulsionar uma ligação particular e, com isso, obter a venda.

Esse processo de gerar uma autoassociação, por parte do indivíduo, com algum produto, item, nome, número ou marca, ficou denominado na literatura por egocentrismo implícito, devido a expressão de traços egocêntricos da personalidade do indivíduo de uma forma inconsciente e implícita que afeta seu comportamento. Para Coulter e Grewal (2014), o egocentrismo implícito refere-se à noção de que as pessoas têm associações positivas sobre si mesmas, e essas associações podem, inconscientemente, transferir valores para os objetos que são associados consigo mesmo.

Assim como a maioria dos estudos que são direcionados à compreensão do indivíduo e sua cognição, o estudo do egocentrismo implícito também é proveniente da psicologia e foi introduzido no ambiente organizacional quando Anseel e Duyck (2008) demonstraram que as pessoas são mais propensas a trabalhar para empresas com as iniciais correspondentes aos próprios nomes do que a trabalhar para empresas com outras iniciais. Do mesmo modo, outros estudos internacionais (e.g., COULTER; GREWAL; 2014) afirmam que consumidores preferem preços em que a primeira letra contenha a letra inicial de seus nomes (e.g., $\mathrm{R} \$ 200,00$ - Duzentos reais e Denise) e que preços com a inclusão dos centavos possam representar a data de nascimento do consumidor (e.g., $\mathrm{R} \$ 15,05$ e 15 de maio).

Os efeitos do egocentrismo implícito no comportamento do consumidor são bastante valiosos para uma mudança na forma de como as empresas se comunicam com seus consumidores, tanto na busca de uma atuação mais personalizada junto aos seus clientes, como para incorporar aspectos dessas autoassociações nas estratégias de divulgação e promoção.

Ao se pesquisar pela aplicação dessa ferramenta por empresas brasileiras, nota-se que ainda não se têm, de maneira evidenciada, casos em que as empresas manipulem dados pessoais objetivando gerar uma autoassociação positiva, porém isso não representa que as organizações não estão cientes e manipulando esses processos inconsistentes, mas ainda não se tem claras evidências desse processo.

Algumas pesquisas internacionais (e.g., ANSEEL; DUYCK, 2008; COULTER; GREWAL; 2014) já foram realizadas objetivando compreender o egocentrismo implícito, porém o estudo dessa temática ainda é bastante incipiente, principalmente na área do comportamento do consumidor no mercado brasileiro, uma vez que pesquisadores nacionais ainda não abordaram investigações sobre esse tipo de comportamento e, por conseguinte, é desconhecido seus efeitos no Brasil. 
É a partir do preenchimento dessa lacuna, da busca por conhecer outros efeitos desse construto e associá-lo com o comportamento do consumidor brasileiro que surge o objetivo desse trabalho, que é verificar como o egocentrismo implícito resultante de autoassociações positivas dos consumidores afeta sua intenção de compra e sua preferência pelos produtos. Os objetivos específicos são os seguintes: i) conhecer a influência do egocentrismo implícito no consumo; e ii) verificar se autoassociações com a letra do nome, a data de nascimento e a crença religiosa podem influenciar o comportamento de compra.

Optou-se por pesquisar o comportamento de compra relacionado às influências religiosas devido ao fato de que $89 \%$ dos brasileiros concordam que a religião é algo importante e priorizou-se o estudo com a religião católica devido ao Brasil ser o país com maior número de católicos do mundo (NERI, 2011). Além disso, seguiu-se a orientação de Muhamad e Mizerski (2010) de que os estudiosos de marketing devem estudar a religião, tendo em vista que influências culturais tem um papel significativo no comportamento do consumidor moderno.

Esse trabalho possui quatro partes. A primeira corresponde a essa introdução. A segunda parte do texto revisa a literatura no tocante aos seguintes temas: egocentrismo implícito, aspectos religiosos no egocentrismo implícito. Em seguida são apresentados os três estudos experimentais com os resultados e discussões em que foi relacionado o consumo de produtos e egocentrismo implícito por meio das letras iniciais dos consumidores, suas datas de nascimento e datas religiosas. Na quinta e última parte do texto são socializadas as considerações finais.

\section{EGOCENTRISMO IMPLÍCITO}

Sabe-se que os indivíduos não são movidos apenas por seus comportamentos conscientes e racionais, muitas emoções, sentimentos ou até mesmo questões que estão em seu inconsciente podem alterar suas percepções e atitudes. Para Dijksterhuis e Bargh (2001), os processos automáticos ou inconscientes desempenham um papel importante em quase todos os processos psicológicos sociais.

Pesquisas em cognição social implícita sugerem que muitos julgamentos e comportamentos mundanos são influenciados por potentes e penetrantes motivos inconscientes (PELHAM; MIRENBERG; JONES, 2002). Essa cognição implícita é responsável por muitas atitudes consideradas fora do racionalismo consciente, ou seja, realidades executadas que fogem do entendimento do executor, mas que possuem uma relação com o mesmo.

Em relação aos comportamentos inconscientes, o egocentrismo implícito é um exemplo que vem ganhando destaque e reflete um processo inconsciente que se baseia nas autoassociações favoráveis das pessoas (PELHAM et al. 2003). Para esses mesmos autores, não existem dúvidas em relação ao fato de que o egocentrismo implícito influencia decisões importantes na vida das pessoas.

Na busca por testar essa abordagem Pelham, Mirenberg e Jones (2002) encontraram correlações que embasam sua hipótese de que escolha da profissão ou até mesmo a escolha da cidade onde morar, possa ter alguma correlação com a semelhança do nome do indivíduo. Por exemplo, pessoas chamadas Denis ou Denise são propensas a exercer a carreira de dentista. 
Como desdobramento do estudo do egocentrismo implícito surgiu o estudo do "efeito nome/letra", que demonstra que as pessoas preferem letras contidas em seus próprios nomes mais do que as outras letras do alfabeto (NUTTIN, 1985; JONES et al, 2004). De acordo com o egocentrismo implícito, a explicação para este efeito se dá devido maioria das pessoas possuírem associações positivas sobre si mesmos, por esta razão a maioria das pessoas orbitam em torno de coisas que se assemelham a si mesmos (PELHAM et al., 2003). Brendl et al. (2005), também encontraram efeito significante no estudo sobre a letra inicial do nome do consumidor na sua intenção de compra da marca e do produto. Coulter e Grewal (2014) atribuem esse gosto/preferência juntamente com a intenção de compra como fundamento geral da compreensão desse efeito tanto pelo número, letra, nome ou outro aspecto relacionado ao egocentrismo implícito. A partir dos apontamentos desses estudos é que surgiu a primeira hipótese dessa pesquisa:

$\mathrm{H} 1$ : Os consumidores demonstram maior intenção de compra e gosto pelo produto quando o produto apresenta letras que se relacionam com o nome do indivíduo.

Coulter e Grewal (2014) demonstram que uma pessoa nascida em 15 de janeiro é mais propensa a comprar um hambúrguer de que custa 4,15 dólares do que um hambúrguer de 4,10 dólares, enquanto uma pessoa nascida em 10 de fevereiro é mais propensa a comprar um hambúrguer que custa 4,10 dólares. Logo, se um estímulo de preço for apresentado visualmente, o consumidor deve fazer a relação entre o número (preço) e a data de seu aniversário. Desta forma, Coulter e Grewal (2014) chamam este fenômeno de birthdaynumber/price effect (em português efeito preço com número da data de aniversário), em que o efeito deve se manifestar como gosto do atributo do preço e aumento da intenção da compra da marca.

Embora existam poucas pesquisas que busquem achar intenção de compra com a relação ao aniversário do cliente e os dígitos em um preço, evidências têm indicado que as pessoas se estimulam positivamente a objetos ou eventos que compartilham números correspondentes aos de seus aniversários (JONES et al., 2004). Brendl et al (2005) também encontraram resultados semelhantes manipulando letras de nomes, sugerindo que estes achados são consequências do egocentrismo implícito.

Por fim, para o presente estudo será utilizado como variável o ano de nascimento do consumidor e o relacionamento com a intenção de compra do produto. Dessa forma apresenta-se a hipótese 2 deste trabalho: $\mathrm{H} 2$ : Os consumidores demonstram maior intenção de compra quando os preços apresentados visualmente (como caracteres numéricos) fazem referência ao ano de nascimento do consumidor.

\section{EGOCENTRISMO IMPLÍCITO E O CONSUMO DE INFLUÊNCIAS RELIGIOSAS}

O egocentrismo implícito sugere que as pessoas prefiram algo que associem a si mesmo. Vários aspectos podem ser incluídos nessa análise, tais como as influências e heranças culturais. Para Delener (1990), as heranças culturais explicam, em parte, o comportamento do consumidor e o comportamento de compra.

Um exemplo desses aspectos influenciadores do comportamento do consumidor é a religião. "A religião é um elemento da cultura que permeia todos os aspectos de uma sociedade" (FAM; WALLER; ERDOGAN, 2004, p. 553). A religião oferece visão de mundo, é forte na orientação de conduta (PRANDI, 2007) e tem uma influência significativa no comportamento do consumidor (MUHAMAD; MIZERSKI, 2010; AL-ISSISS, 2010). 
Alguns estudos têm sido feitos relacionando religião com consumo. Delener (1990) explorou os efeitos das variáveis religião e religiosidade na percepção de risco nas decisões de compra. Fam, Waller e Erdogan (2004) analisaram a influência que a religião e a intensidade da crença tem sobre atitudes em relação à publicidade de determinados produtos e serviços controversos.

Outro estudo importante foi o de Muhamad e Mizerski (2010), onde foi encontrado que a influência da religião no comportamento do consumidor pode ser mediada através de cinco fatores; incluindo a filiação de uma pessoa religiosa, seu compromisso com crenças e práticas religiosas, a extensão de seu conhecimento religioso em suas visões e percepções sobre as questões sociais, e sua motivação em seguir sua religião.

Os estudos supracitados relacionaram as variáveis religião e consumo sob um caráter mais teórico. Propõe-se investigar, por meio de uma pesquisa experimental, a relação do egocentrismo implícito no consumo relacionado às datas com significação religiosa.

A partir desse contexto, será investigado essa relação entre consumidores católicos e sem religião. "Diferenças nas afiliações religiosas tendem a influenciar a forma como as pessoas vivem, as escolhas que fazem, o que comem e a quem se associam" (FAM; WALLER; ERDOGAN, 2004, p. 537). A escolha da religião como enfoque ocorreu devido ao fato de que o Brasil é o país com o maior número de católicos no mundo e $89 \%$ dos brasileiros concordam que a religião é algo importante para eles (NERI, 2011). Com base nessas premissas, propõe-se a terceira e última hipótese:

H3: Os consumidores demonstram maior intenção de compra e gosto pelo produto quando há visivelmente estampado no produto referência a uma data religiosa da qual o consumidor faz parte.

Com o intuito de testar as hipóteses propostas, foram elaborados três estudos distintos. No Estudo 1 foi testado se a associação do produto ao nome do indivíduo altera seu gosto pelo produto e sua intenção de compra. No Estudo 2 foi testado se a associação do preço do produto com a data de nascimento do indivíduo altera seu gosto pelo produto e sua intenção de compra. Por último, no Estudo 3, foi verificado se produtos que apresentam datas religiosas alteram o gosto pelo produto e sua intenção de compra sobre quem possue orientação religiosa.

\section{Estudo 1 - Autoassociações entre primeira letra do nome e estampa de produtos}

Considerando que as investigações prévias documentam incidências da existência do egocentrismo implícito e suas influências nas principais decisões da vida do indivíduo, o Estudo 1 tem o propósito de investigar como a primeira letra do nome pode motivar um aumento na intenção de compra de consumidores. No Estudo 1 realizado, foi apresentada uma camisa, na qual havia estampado a primeira letra do nome do respondente. Esperava-se neste caso, quando os respondentes forem expostos a situação em que a estampa da camisa coincide com a primeira letra de seu nome, eles tenderiam a aumentar a intenção de compra pelo produto. 
Participantes e design do experimento

A amostra final do experimento constou com 88 respondentes. O pré-teste foi realizado e aferido alterações no questionário, sendo esses excluídos da amostra final. A operacionalização da pesquisa se deu em sala de aula, com estudantes de diversos cursos de uma universidade localizada em uma capital brasileira, totalizando 88 respondentes, $84 \%$ possuem entre 18 e 24 anos, $12 \%$ possuem 25 a 34 anos, $3 \%$ de 35 a 44 anos e $1 \%$ possuem mais que 44 anos. Os respondentes do sexo feminino representaram $46 \%$ da amostra e do sexo masculino $54 \%$. O desenho experimental single factor foi de 2 (respondentes com a camisa exposta com a letra inicial de seu primeiro nome versus respondentes com a camisa exposta com a letra diferente de seu primeiro nome) x 2 (Intenção de Compra e Gosto pelo Produto). Todos os respondentes indicaram a intenção de compra e houve a manipulação em separar o grupo controle (camisa com exposição de letra diferente do nome inicial do respondente) e o grupo experimental (camisa com exposição de letra igual ao nome inicial do respondente).

\section{Procedimentos e estímulos}

Os participantes foram convidados a participar de um cenário de compra. O produto escolhido foi uma camisa/blusa por ser algo de desejo para homens e mulheres. A camisa/blusa foi um modelo básico sem desenhos e em cores neutras, onde o que ficaria mais em evidência seria o único elemento estampado que foi uma letra do alfabeto.

Os pesquisadores detinham previamente uma base de dados com os nomes das pessoas participantes e a entrega do questionário foi realizada de forma manipulada, sendo entregue a cada respondente o questionário que continha a blusa com a inicial do nome do respondente. Para realizar a comparação foi feito o grupo controle cuja letra apresentada não possui relação com o nome do pesquisado.

O instrumento de coleta de dados consistiu em um questionário, cujos itens de identificação do perfil socioeconômico tratavam-se de faixa etária, sexo e renda. No questionário constavam escalas relacionadas aos dois construtos pesquisados, intenção de compra e gosto pelo produto, sendo utilizadas escalas já validadas. Em relação a primeira escala, três itens mediram a intenção do consumidor de comprar um produto com base nas informações que tenham visto no produto (DODDS; MONROE; GREWAL, 1991). A segunda escala foi adaptada do estudo de Coulter e Grewal (2014), onde três itens mensuraram o gosto pelo produto apresentado.

\section{Resultados}

A primeira etapa é verificar as medidas de dimensionamento das escalas por meio da confiabilidade estavam conforme as indicações de Hair et al., 2005. Os resultados foram satisfatórios quanto ao Alfa de Cronbach maior que 0,70 (0,949 para ambos os construtos Intenção de Compra e Gosto pelo Produto). Dessa forma, pode-se afirmar que cada construto possui confiabilidade satisfatória. 
A aplicação do procedimento estatístico ANOVA obteve um resultado inicial para o teste de homogeneidade (teste de Levene) que permite-nos averiguar da homogeneidade das variâncias, cujos valores foram significantes da ordem de 0,054 com estatística Levene igual a 3,827 para o construto Gosto pelo Produto e de significância 0,957 com estatística Levene igual a 0,003 para o construto Intenção de Compra.

A análise foi feita comparando os dois grupos, grupo com a letra na camisa similar a primeira letra do nome e grupo com letra diferente no primeiro nome. As médias apresentaram diferenças significativas tanto para o construto gosto pelo produto, quanto para o construto intenção de compra, na ordem de 0,006 e 0,32, respectivamente. Os valores de $\mathrm{F}$ foram 8,072 para o construto gosto pelo produto e 4,747 para o construto intenção de compra. Para a significância de 0,05 valores com $F$ maior que 3,84 demostram que as médias não são iguais (HAIR et al., 2005).

Os valores encontrados corroboram para a não refutação da hipótese 1 , de que os consumidores demonstram maior intenção de compra e gosto pelo produto quando o produto apresenta letras que se relacionam com o nome do indivíduo. Nos Gráficos 1 e 2 fica possível conhecer as diferenças existentes entre as médias dos grupos com e sem letras pertencentes aos nomes dos respondentes.

\section{Gráfico 1 - Diferença entre as médias do construto gosto pelo produto.}

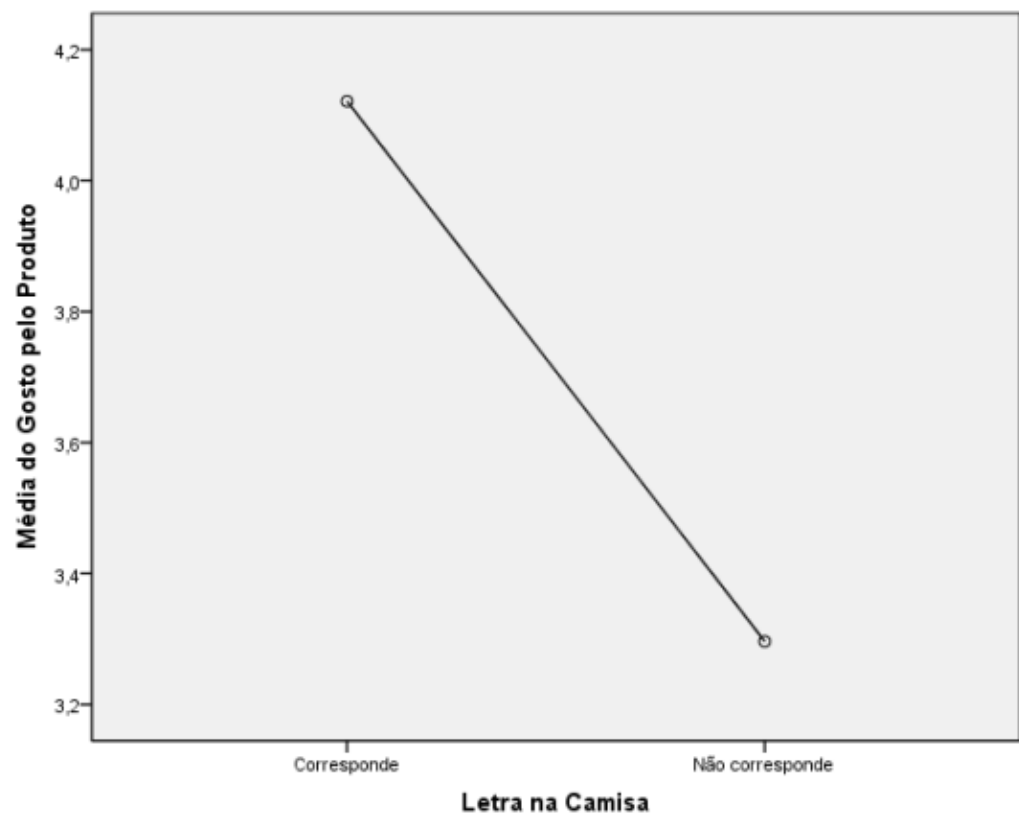

Fonte: dados da pesquisa. 


\section{Gráfico 2 - Diferença entre as médias do construto intenção de compra.}

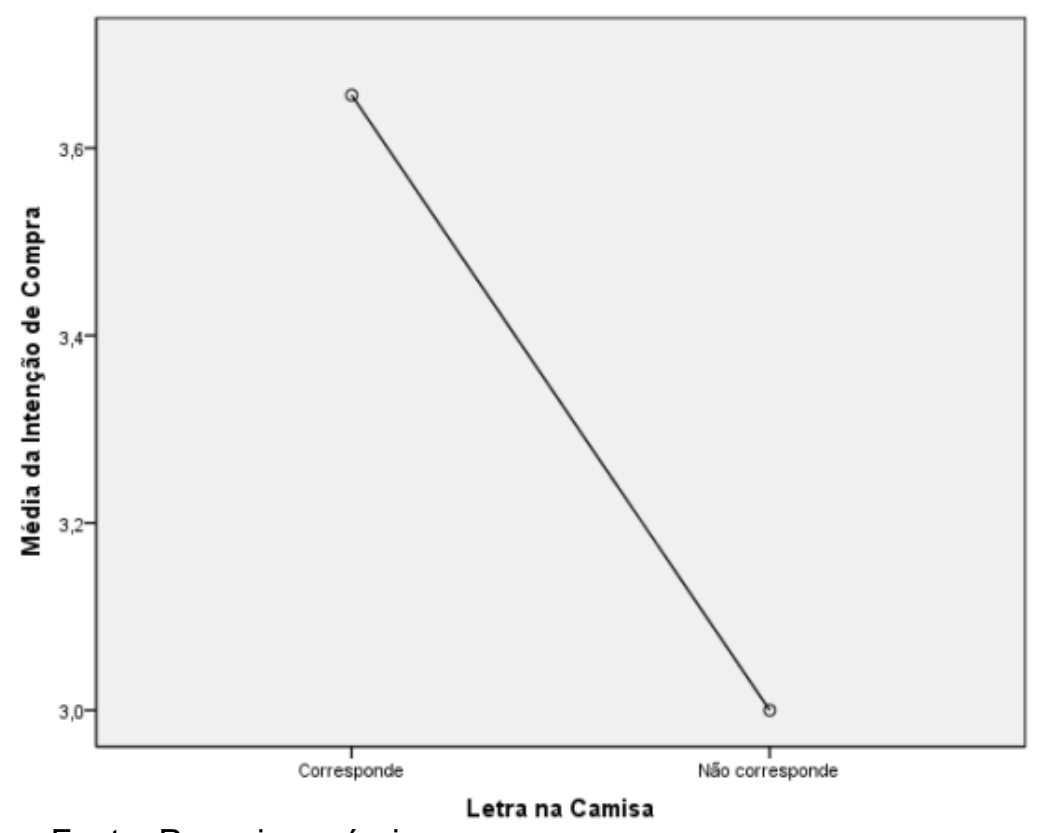

Fonte: Pesquisa própria.

Discussões

Os resultados do estudo 1 demonstraram que o egocentrismo implícito pode influenciar as escolhas individuais. Devido a essas autoassociações positivas, os indivíduos podem ter um maior gosto pelo produto ofertado e até mesmo ter uma maior intenção de compra dos itens que possuem letras relacionadas ao seu próprio nome.

Esse resultado confirma a hipótese 1 e fortalece os achados preliminares de que o efeito nome/letra influenciam os comportamentos e atitudes e podem ser fortes orientadores de condutas e escolhas (COULTER; GREWAL, 2014; PELHAM; MIRENBERG; JONES, 2002; NELSON; SIMMONS, 2007).

\section{Estudo 2 - Autoassociações entre data de nascimento e preço dos produtos}

Visto que as pessoas preferem os números de seus próprios aniversários a números que não são de seus próprios aniversários (BRENDL et al., 2005), o Estudo 2 tem o propósito de investigar como a data de nascimento pode influenciar na intenção de compra de consumidores. No experimento realizado foi apresentado um anúncio promocional de um sanduíche com batatas fritas e refrigerante, no qual havia o preço da promoção, e este valor coincidia com o ano de nascimento do entrevistado. Esperava-se neste caso, quando os respondentes fossem expostos a situação em que o preço do anúncio coincide com seu ano de nascimento, eles tenderiam a aumentar a intenção de compra pelo produto. 
Participantes e design do experimento

O segundo experimento contou com amostra final de 87 respondentes. Foi realizado o pré-teste com sete respondentes e aferidas pequenas alterações nas perguntas/afirmativas presentes no questionário, sendo esses excluídos da amostra final. Dos 87 respondentes, $84 \%$ possuem entre 18 e 24 anos, $12 \%$ entre 25 a 34 anos, $3 \%$ entre 35 a 44 anos e $1 \%$ com mais que 44 anos. Os respondentes do sexo feminino representaram $46 \%$ da amostra e do sexo masculino $54 \%$.

O desenho experimental single factor foi de 2 (respondentes onde o algarismo numérico do preço do produto correspondia a seu ano de nascimento versus respondentes cujo o algarismo numérico do preço do produto não correspondia com o seu ano de nascimento) x 2 (Intenção de Compra e Gosto pelo Produto). Todos os respondentes indicaram a intenção de compra e houve a manipulação em separar o grupo controle (algarismo numérico do preço diferente do ano de nascimento do respondente) e o grupo experimental (algarismo numérico do preço do produto correspondia com o ano de nascimento do respondente). Para que o preço não influenciasse em uma maior intenção de compra, o grupo experimental foi composto por pessoas que nasceram entre os anos de 1990 a 1998, sendo assim, desta forma os preços de seus produtos variaram entre 19,90 reais a 19,98 reais coincidindo com o ano de nascimento. No grupo controle foi utilizado o preço praticado de 19,99 reais, portanto a variação do preço do grupo experimental e do grupo controle foi de cerca de $0,5 \%$ do produto $(19,90$ reais a 19,99 reais $)$.

\section{Procedimentos}

Assim como no primeiro experimento os respondentes foram convidados a participar de um cenário de compra. O produto escolhido foi um combo de sanduíche, refrigerante e batata frita muito comum nas lanchonetes e fast foods. Ressalta-se que os mesmos não possuíam marca, nem emblemas e a única informação era o valor daquele kit/combo. O produto era apresentado através de um anúncio comercial e o algarismo numérico do preço desse produto correspondia ao ano de nascimento do respondente (preço de R\$ 19,90 para quem havia nascido no ano de 1990). Para uma aplicação precisa, os pesquisadores já detinham de uma base de dados com as datas de nascimento e a entrega do questionário ocorreu de uma forma manipulada. Para realizar a comparação foi feito o grupo controle cujo valor apresentado não possuía relação com o ano de nascimento do respondente. $O$ instrumento de coleta de dados seguiu as mesmas escalas do Estudo 1 para ambos os construtos Gosto pelo Produto (COULTER; GREWAL, 2014) quanto para Intenção de Compra (DODDS; MONROE; GREWAL, 1991).

\section{Resultados}

A primeira etapa foi novamente verificar as medidas de dimensionamento das escalas por meio da confiabilidade estavam conforme as indicações de Hair et al., 2005. Os resultados foram satisfatórios quanto ao Alfa de Cronbach maior que 0,70 (0,900 para o construto Intenção de Compra e 0,805 para o construto Gosto pelo Produto). Dessa forma, pode-se afirmar que cada construto possui confiabilidade satisfatória. 
Ao aplicar do procedimento estatístico ANOVA obteve-se resultado para o teste de homogeneidade (teste de Levene) de significância 0,404 para o construto Gosto pelo Produto e de 0,004 para o construto Intenção de Compra. Neste caso somente o construto Gosto pelo Produto se fez significante em relação à homogeneidade. A análise foi feita comparando os dois grupos: i) o preço da promoção coincide com o ano de nascimento do respondente; e ii) o preço da promoção não coincide com o ano de nascimento do respondente. A diferença entre as médias não apresentou significância nem para o construto Gosto pelo Produto, nem para o construto Intenção de Compra, que resultaram 0,463 e 0,943 respectivamente. Ressaltese que para esse caso, foram usados os testes de Welch e Brown-Forsythe e para ambos os casos as significâncias foram maiores que 0,005 (0,457 e 0,948, respectivamente).

Os valores encontrados corroboram para a refutação da hipótese 2, em que os consumidores demonstram maior intenção de compra quando os preços apresentados visualmente (como caracteres numéricos) fazem referência ao ano de nascimento do mesmo.

\section{Discussões}

Os resultados do Estudo 2 refutaram a hipótese 2. Neste caso foi testado se o ano de nascimento no preço do produto apresentado acarretaria na propensão à compra do produto. Diferentemente do que foi testado em estudos anteriores, nos quais investigaram se haveria propensão ao consumo, caso o preço apresentado coincidisse com o dia do aniversário do respondente da pesquisa (COULTER; GREWAL, 2014; BRENDL, 2005).

Desta forma, chega-se à conclusão de que o consumidor brasileiro não se autorelaciona de forma significativa com o ano de nascimento, tanto quanto com o dia de nascimento. Um fator que pôde ter reduzido a propensão à compra é o fato de ter sido apresentado um combo de sanduíche, refrigerante e batata frita e os respondentes que não consomem este tipo de produto não se sentiram propensos a comprar e não refletiram sentimentos positivos ao produto.

\section{Estudo 3 - Egocentrismo Implícito nas Crenças Religiosas}

Esse estudo foi pautado no propósito de testar como a influência das crenças religiosas altera a intenção de compra do consumidor. Acredita-se que quem possui orientação religiosa de base católica possui mais intenção de compra quando o produto apresentado possuía em sua estampa, uma data de forte apelo religioso católico. A religião católica foi escolhida devido ao Brasil ser o país com maior número de católicos do mundo (NERI, 2011).

O estudo considera o egocentrismo implícito nas crenças religiosas devido ao fato de não estar oferecendo um produto claramente religioso ao consumidor. Neste experimento não há imagens ou símbolos religiosos estampados, logo o participante foi influenciado a comprar o produto por aspectos implícitos associados a heranças culturais e escolha religiosa. 
No experimento realizado, foi apresentada uma blusa/camisa com um número de cunho religioso e questionado sobre a intenção de compra sobre o mesmo. Ao final do questionário o respondente deveria escolher entre as opções: i) não possuo orientação religiosa; ii) possui orientação religiosa de base católica; e iii) possuo orientação religiosa de base não católica. A análise foi feita tendo em vista as opções dos respondentes que possuíam religião com orientação católica, confrontando com os sem orientação religiosa e não católicos.

Participantes e design do experimento

A amostra final do experimento em questão foi constituída de 77 respondentes. Foi realizado préteste com sete respondentes e aferidas pequenas alterações nas perguntas/afirmativas presentes no questionário, sendo esses excluídos da amostra final. Dos 77 respondentes, $61 \%$ possuem entre 18 e 24 anos, $29 \%$ entre 25 e 34 anos, $6 \%$ entre 35 e 44 anos e $4 \%$ possuem mais que 44 anos. Os respondentes do sexo feminino representaram $51 \%$ da amostra e do sexo masculino $49 \%$. Tratando da orientação religiosa, $15 \%$ afirmaram não possuir orientação religiosa, $64 \%$ afirmaram possuir orientação religiosa de base católica e $21 \%$ afirmaram possuir orientação religiosa de base não católica.

O desenho experimental single factor foi de 2 (respondentes com orientação religiosa de base católica versus respondentes sem orientação religiosa e sem base católica) x 2 (Intenção de Compra e Gosto pelo Produto). Nesse experimento aqueles que declararam não possuir orientação religiosa ou possuir orientação de base não católica foram considerados do grupo controle e os que declararam possuir orientação religiosa de base católica foram considerados do grupo experimental, pois o procedimento a ser controlado utiliza aspectos estritamente católicos.

\section{Procedimentos e estímulos}

Os procedimentos do Estudo 3 foram semelhantes ao Estudo 1, pois o produto foi uma blusa, sem desenhos e de cor neutra. No caso desse experimento o que constava como estampa da blusa era um número com conotação religiosa católica, mais especificamente a data 13/05 (treze de maio), dia de Nossa Senhora de Fátima, data popular entre católicos da região em que foi realizada a pesquisa. Os questionários foram entregues aleatoriamente, visto que o que iria segregar a amostra era a pergunta que constava no final do questionário sobre a orientação religiosa do respondente.

$\mathrm{O}$ instrumento de coleta de dados seguiu as mesmas escalas do Estudo 1 para ambos os construtos Gosto pelo Produto (COULTER; GREWAL, 2014) quanto para Intenção de Compra (DODDS; MONROE; GREWAL, 1991). 


\section{Resultados}

A primeira etapa foi verificar se as medidas de dimensionamento das escalas por meio da confiabilidade estavam conforme as indicações de Hair et al., 2005. Os resultados foram satisfatórios quanto ao Alfa de Cronbach maior que 0,70 (0,961 para o construto Intenção de Compra e 0,951 para o construto Gosto pelo Produto). Dessa forma, pode-se afirmar que cada construto possui confiabilidade satisfatória.

Gráfico 3 - Diferença entre as médias do construto gosto pelo produto.

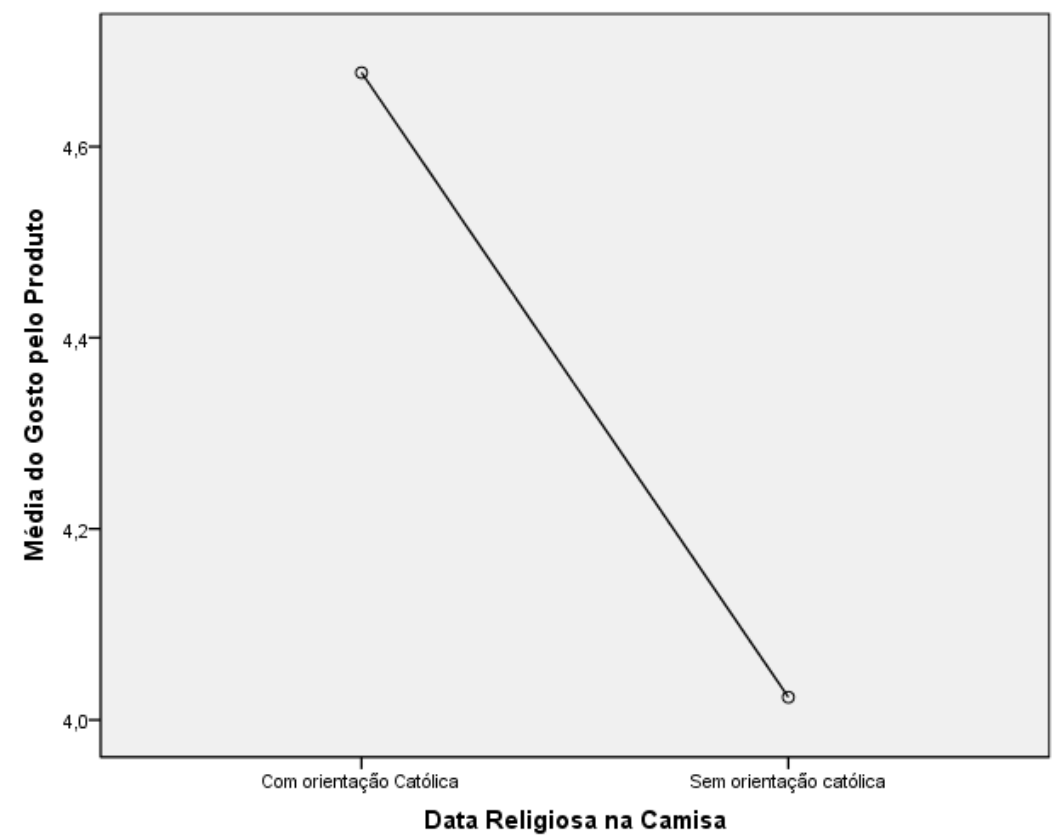

Fonte: dados da pesquisa.

Gráfico 4 - Diferença entre as médias do construto intenção de compra.

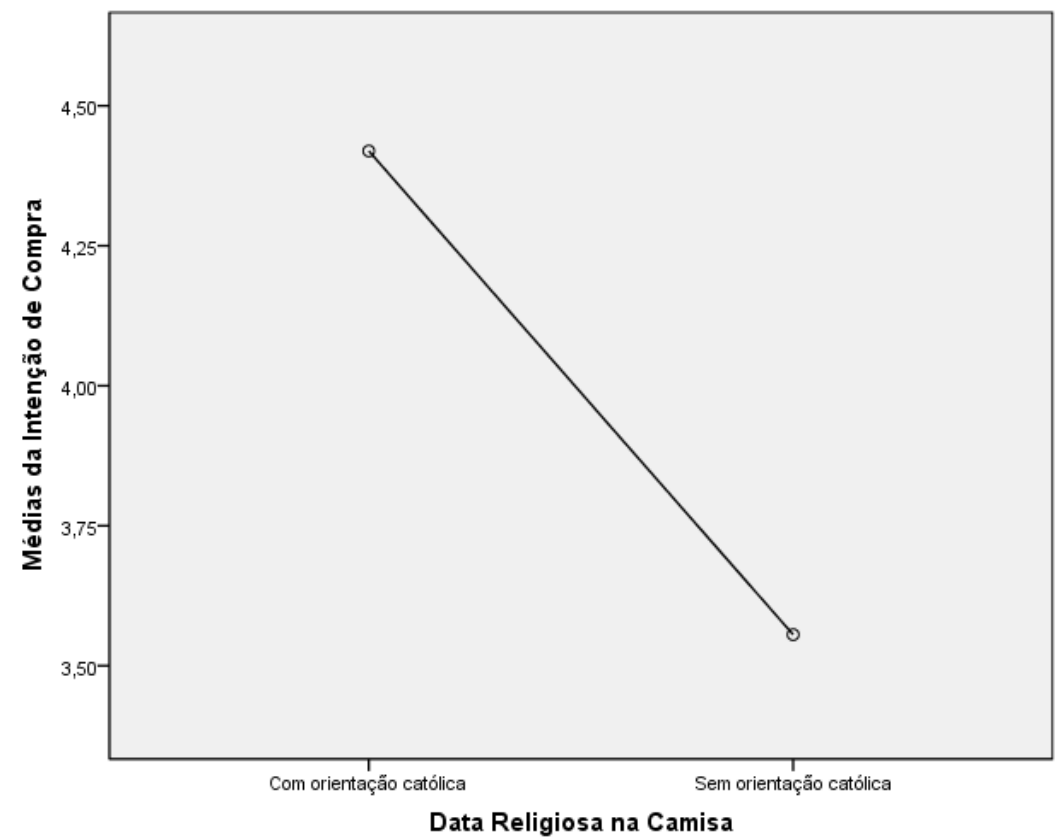

Fonte: dados da pesquisa. 
A análise foi feita comparando a diferença entre os grupos para os construtos intenção de compra e gosto pelo produto. Os grupos foram divididos em: i) respondentes com orientação religiosa de base católica e ii) respondentes sem orientação religiosa ou com orientação de base não católica. Em relação a construto gosto pelo produto, a média entre os grupos apresentou o valor de 7,619, com significância de 0,048 e com o valor de $F$ igual a 4,045. Para o construto intenção de compra a média entre os grupos foi de 13,308 , com significância de 0,027 e valor de $F$ igual a 5,113. Em relação a orientação religiosa, $F$ possui o valor de 29,748 com significância de 0,000.

Os valores encontrados corroboram para a aceitação da hipótese $\mathrm{H} 3$ de que os consumidores demonstram maior intenção de compra e gosto pelo produto quando há visivelmente estampado referência a uma data religiosa do qual o consumidor faz parte. Pode ser verificado pela apresentação dos Gráficos 3 e 4 , confirmando os resultados supracitados.

\section{Discussões}

Os resultados do Estudo 3 corroboraram com o pressuposto que os efeitos das autoassociações positivas podem influenciar as escolhas e comportamentos. Nesse caso, adicionou-se mais um cenário nessa análise: a relação com a orientação religiosa, já que ficou evidenciado que a religião é um dos fatores que se pode gerar uma autoassociação positiva e com isso alterar a percepção do envolvido.

Com esse estudo foi possível concluir que a hipótese 3 foi confirmada, já que foi verificado que produtos com conotação religiosa podem elevar o sentimento pelo gosto do produto e também pela intenção de compra do consumidor.

\section{CONSIDERAÇÕES FINAIS}

Novas maneiras de desvelar o comportamento do consumidor motivam os pesquisadores e empresários a estudar as características e idiossincrasias no consumo e como as decisões de compra são tomadas. A partir disso, estudos cada vez mais peculiares e específicos são realizados e novas alçadas são transpostas. Pesquisar comportamentos inconscientes tornou-se primoroso para estudiosos do marketing, visto que processos inconscientes podem afetar escolhas e práticas de consumo.

Nessa pesquisa três estudos foram realizados no intuito de conhecer como associações inconscientes podem afetar as escolhas dos consumidores e até mesmo alterar sua percepção sobre produtos e marcas. Nos Estudos 1 e 2 foram testados fenômenos já trabalhados por outros autores, como o efeito de letras do nome e de datas de nascimento. Coulter e Grewal (2014) testaram cenários sobre esses dois efeitos e tiveram resultados valorosos. Defrontando os achados, percebe-se que ambos tiveram achados com significância estatística nos estudos com o efeito nome da letra, o que reforça essa teoria também no Brasil. Já no estudo do efeito das datas, o presente estudo não achou efeitos significantes, diferindo dos resultados de Coulter e Grewal (2014) e levantando, com isso, um questionamento sobre esse efeito e se existe diferença na percepção de estadunidenses e brasileiros.

Em relação a não significância do Estudo 2, pode-se levantar algumas vulnerabilidades da pesquisa que podem ter afetado o resultado final. Primeiramente, o tipo de alimento apresentado, os combos 
sanduíche, refrigerante e batata frita são bem típicos de restaurantes fast food e não foi averiguado antecipadamente se os respondentes possuem dietas vegetarianas e se consomem esse tipo de alimento. Ademais, sabe-se que se passa por uma fase de ênfase em produtos saudáveis. Outro ponto é que pelo produto apresentado ser um alimento de consumo imediato, refeições próximas ao momento da aplicação do questionário podem ter diminuído o interesse pelo alimento e, consequentemente, a propensão à compra.

Com o resultado estatisticamente significante do Estudo 3, foi possível incorporar um novo efeito à teoria do egocentrismo implícito, o efeito crenças religiosas, no qual crenças individuais também são fatores que geram associações positivas. Do conhecimento dos autores, esse foi o primeiro trabalho que pesquisou o egocentrismo implícito relacionado às crenças religiosas. Portanto, há um preenchimento de uma importante lacuna teórica. Por fim, sugere-se a necessidade de estudar outras religiões e contextos no Brasil e em outros países para trazer à academia novos caminhos sobre o egocentrismo implícito no consumo de produtos e serviços religiosos.

Implicações gerenciais, teóricas e éticas

É de grande importância que empresários compreendam que a massificação das propagandas e divulgações não é um ponto resoluto e findado. Nota-se que as particularidades individuais fazem uma grande diferença nas escolhas e, por isso, as empresas devem conhecer melhor seus clientes e dar mais enfoque na personalização e na tipificação das propagandas. A desmistificação da propaganda em massa é, certamente, um ponto chave das implicações gerenciais desse estudo. Além da personalização da divulgação, pode-se indicar, de uma maneira mais avançada na personalização do próprio produto, isso é possível quando se conhece os gostos individuais de seus consumidores. Os usos de bancos de dados no marketing podem ser tratados de outra forma, ao invés de usá-los como meio de chegar a todos, pode-se usá-los como meio de chegar a cada um. Conhecer os efeitos do egocentrismo implícito é uma grande oportunidade para as empresas de alterar o modo de fazer negócios.

Como implicações teóricas, este trabalho abre campo para novos desdobramentos dos estudos do egocentrismo implícito. Espera-se que com essa pesquisa novos estudos sejam realizados testando outros efeitos no Brasil, visto que esse país apresenta aspectos bem peculiares e próprios. Almeja-se, também, que mais estudos comparativos possam ser realizados e que outros efeitos de associações pessoais sejam aferidos.

Abre-se aqui um questionamento sobre até que ponto essas pesquisas com o inconsciente humano podem levar empresas a agir de forma não ética e coletarem informações que induzam o consumo de uma forma prejudicial e soberba. Salienta-se ao envolvidos, empresas e clientes, sobre o cuidado na tratativa desses dados e sobre o fornecimento de informações de cunho pessoal.

\section{Limitações e sugestões para futuros trabalhos}

Além das limitações outrora citadas do Estudo 2, foram verificados outros pontos que podem ser indicados, como o fato de o estudo ter sido realizado em apenas um estado brasileiro, impossibilitando a generalização dos resultados. Ademais, os tamanhos das amostras variaram entre 77 e 88 respondentes. 
Sugere-se para futuros trabalhos verificar o efeito do egocentrismo implícito associada a pessoas próximas, como a intenção de compra para produtos com datas e nomes de filho e pais. Sugere-se, também, verificar se esse efeito está relacionado com a necessidade de autoafirmação.

Nesse estudo testou-se a associação com números de conotação religiosa. Sabe-se que o Brasil é um país majoritariamente católico e isso, certamente, impactou no resultado da pesquisa. Nesse caso, questiona-se como esse efeito pode ser trabalhado em outros contextos e países e como outros efeitos podem ser testados tentando agregar mais robustez à teoria do egocentrismo implícito.

\section{REFERÊNCIAS}

AL-ISSISS, Mohamad. The Impact of Religious Experience on Financial Markets. Harvard Kennedy School of Government. Al-Khazali, OM, Koumanakos, EP, \& Pyun, CS (2008). Calendar anomaly in the Greek stock market: Stochastic dominance analysis. International Review of Financial Analysis, v. 17, n. 3, p. 461-474, 2010.

ANSEEL, Frederik; DUYCK, Wouter. Unconscious applicants: A systematic test of the name-letter effect. Psychological Science, v. 19, n. 10, p. 1059-1061, 2008.

BRENDL, C. Miguel et al. Name letter branding: Valence transfers when product specific needs are active. Journal of Consumer Research, v. 32, n. 3, p. 405-415, 2005.

COULTER, Keith S.; GREWAL, Dhruv. Name-Letters and Birthday-Numbers: Implicit Egotism Effects in Pricing. Journal of Marketing, v. 78, n. 3, p. 102-120, 2014.

DELENER, Nejdet. The effects of religious factors on perceived risk in durable goods purchase decisions. Journal of Consumer Marketing, v. 7, n. 3, p. 27-38, 1990.

DIJKSTERHUIS, Ap; BARGH, John A. The perception-behavior expressway: Automatic effects of social perception on social behavior. Advances in experimental social psychology, v. 33, p. 1-40, 2001.

DODDS, William B.; MONROE, Kent B.; GEWAL, Dhuv. The Effects of Price, Brand, and Store Information on Buyer's Product Evaluations. Journal of Marketing Research, v. 28, n.3, p. 307-319, 1991.

FAM, Kim Shyan; WALLER, David S.; ERDOGAN, B. Zafer. The influence of religion on attitudes towards the advertising of controversial products. European Journal of Marketing, v. 38, n. 5/6, p. 537-555, 2004.

HAIR, Joseph; ANDERSON, Rolph; TATHAM, Ronald; BLACK, William. Análise Multivariada de Dados. Tradução de Adonai Schlup Sant'anna e Anselmo Chaves Neto. 5 ed., Porto Alegre: Bookman, 2005.

JONES, John T. et al. How do I love thee? Let me count the Js: implicit egotism and interpersonal attraction. Journal of Personality and Social Psychology, v. 87, n. 5, p. 665, 2004.

KOOLE, S.L. et al. On the Nature of Implicit Self-Esteem: The Case of the Name Letter Effect. The Ontario symposium, v. 9, p. 93-116, 2003.

MUHAMAD, Nazlida; MIZERSKI, Dick. The constructs mediating religions' influence on buyers and consumers. Journal of Islamic Marketing, v. 1, n. 2, p. 124-135, 2010.

NELSON, Leif D.; SIMMONS, Joseph P. Moniker Maladies When Names Sabotage Success. Psychological Science, v. 18, n. 12, p. 1106-1112, 2007.

NERI, Marcelo Cortes; DE MELO, Luísa Carvalhaes Coutinho. Novo Mapa das Religiões (New Map of Religions). Horizonte, v. 9, n. 23, p. 637-673, 2011.

NUTTIN, Jozef M. Narcissism beyond Gestalt and awareness: The name letter effect. European Journal of Social Psychology, v. 15, n. 3, p. 353-361, 1985.

PELHAM, Brett W.; CARVALLO, Mauricio R.; DeHART, Tracy; JONES, John T. Assessing the Validity of Implicit Egotism: A Reply to Gallucci. Journal of Personality and Social Psychology, v. 85, n. 5, p. 800-807, 2003.

PELHAM, Brett W.; MIRENBERG, Matthew C.; JONES, John T. Why Susie sells seashells by the seashore: implicit egotism and major life decisions. Journal of Personality and Social Psychology, v. 82, n. 4, p. 469, 2002.

PRANDI, Reginaldo. As Religiões e as Culturas: Dinâmica Religiosa na América Latina. Disponível em: <http://www.fflch.usp.br/sociologia/prandi/>. Conferência Inaugural das XIV Jornadas Sobre Alternativas Religiosas na América Latina. Buenos Aires 25 a 28 de setembro de 2007. Acesso em 4 out. 2014. 